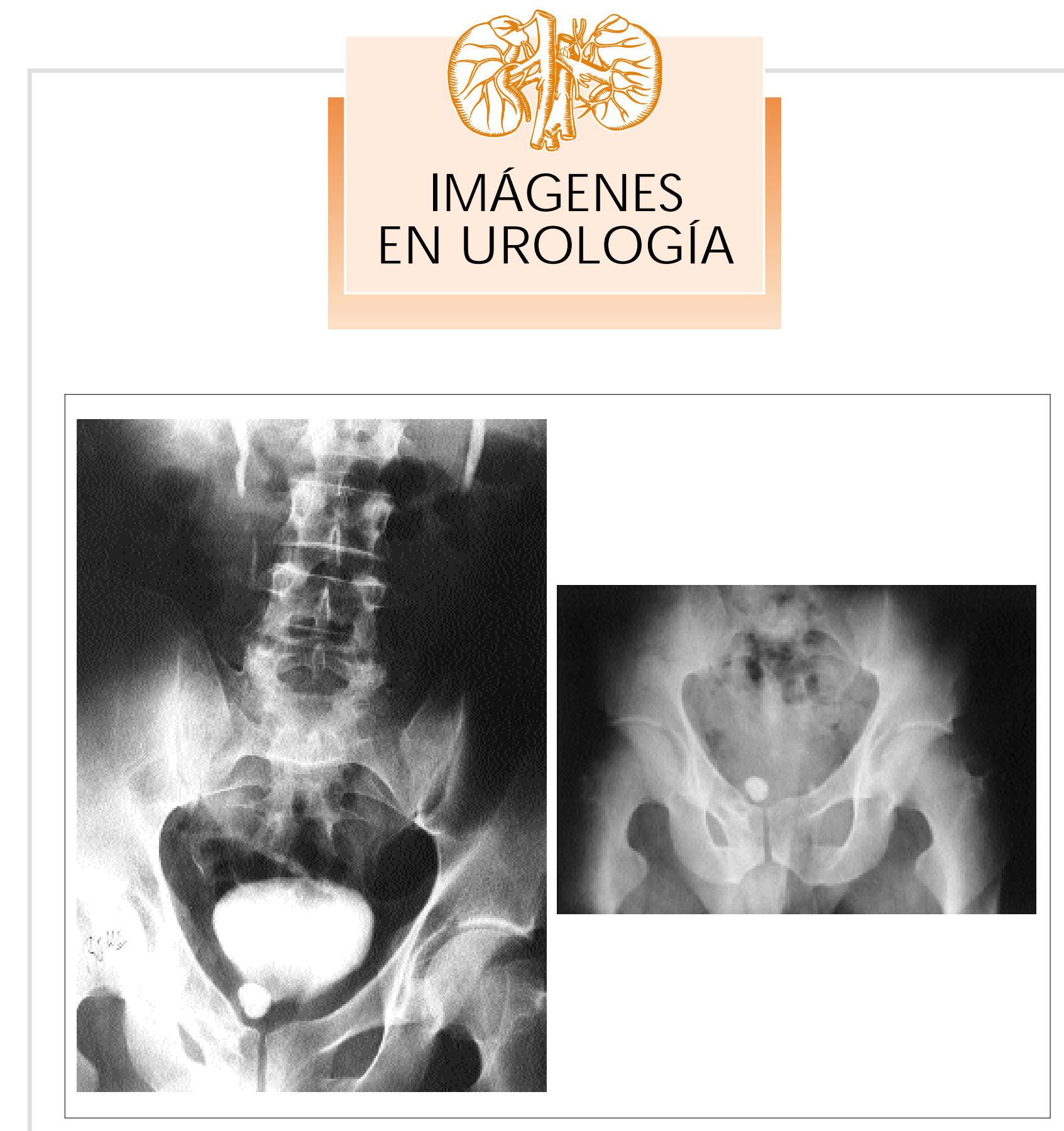

\title{
LESIÓN VESICAL SECUNDARIA A FRACTURA DE PELVIS
}

Varón de 29 años que sufre fractura traumática de rama isquiopubiana derecha. Meses después refiere dolor hipogástrico coincidiendo con la micción así como episodios ocasionales de hematuria macroscópica.

En la Rx de pelvis y U.I.V. se observa una calcificación dependiente de la rama pubiana derecha que parece contactar con la vejiga. La cistoscopia demostró que dicha calcificación estaba incrustada en la pared vesical anterior aunque la mucosa conservaba su integridad.

Se intervino quirúrgicamente a través de una laparotomia media infraumbilical. La pared vesical anterior estaba firmemente adherida al pubis como consecuencia del fragmento de hueso incrustado en la misma que fue finalmente extirpado.

J. Lema Grille, M. Blanco Parra*, A. Cimadevila García, H. Rodríguez Núñez, P. Lamas Cedrón Servicio de Urología. *Facultad de Medicina.

Hospital Clínico Universitario. Santiago de Compostela. A Coruña. 


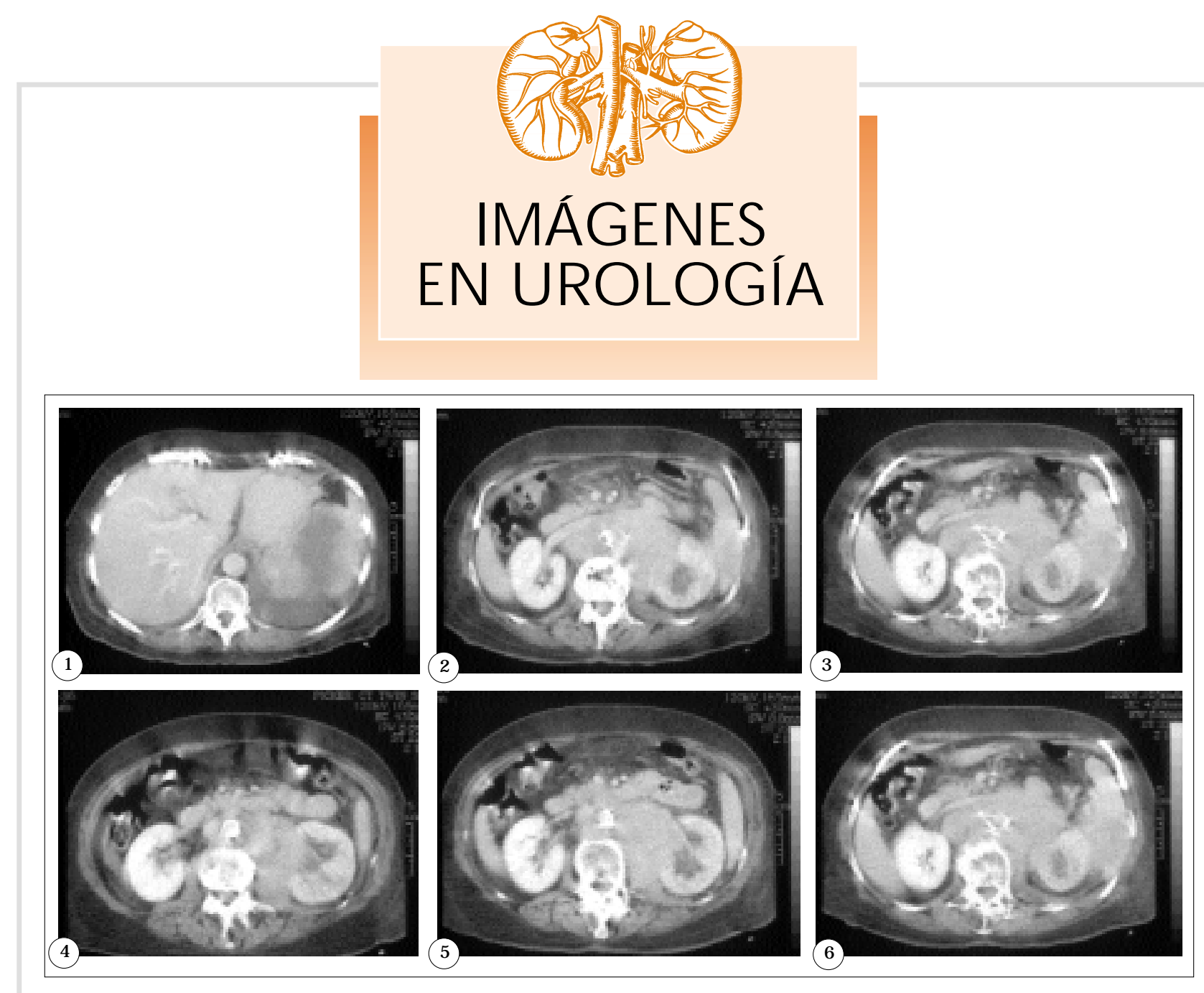

\section{LINFOMA NO HODGKIN RETROPERITONEAL CON COMPROMISO RENAL. A PROPÓSITO DE UN CASO}

Paciente de 54 años de edad en estudio por el Servicio de Hematología, por enfermedad linfoproliferativa.

Se nos solicita colaboración ante hallazgo en TAC de masa retroperitoneal de grandes dimensiones que engloba y compromete la función del riñón izquierdo.

Se realiza exploración quirúrgica con nefrectomía izquierda y exéresis de la mayor parte posible de la masa.

La Anatomía Patológica resultante es un LNH difuso de célula grande B, siendo un estadio III A (el paciente presenta además adenopatias mediastinicas, y no presenta fiebre, sudoración ni pérdida de peso).

El paciente se encuentra bajo control y tratamiento por parte del Servicio de Hematologia, con Quimioterapia sistémica tipo CHOP (ciclofosfamida, adriamicina, vincristina y prednisona). La duración del tratamiento es de seis ciclos, instaurándose cada ciclo un día cada tres semanas.

Iconografia: Figuras 1, 2, 3, 4 y 5. Gran masa linfoproliferativa (LNH), que engloba y comprometa la función del riñón.

M.A. García García, M.A. Trivez Boned, D. Pascual Regueiro,

C. Sancho Serrano, A. Borque Fernando, L.A. Rioja Sanz

Servicio de Urología. Hospital Universitario Miguel Servet. Zaragoza. 